\title{
Some Thoughts on Collaboration
}

\section{Professor Dr. Jan de Boer}

More than 100 generations of medical doctors have passed since the oath of Hippocrates was formulated ( $\pm 400 \mathrm{BC})$. Since then, the medical world has centered around the patient, whether he requires treatment for an elective or emergency situation. Many medical emergencies are possible, varying from a single event to a mass casualty situation. Single events occur more frequently, both inside and outside the hospital, than do mass casualty events; therefore, medical personnel concerned with the former outnumber the doctors concerned with the later. This is reflected in the number of members of the various professional societies. Whether these societies are large or small, rich or poor, they still have one thing in common: the medical emergency of the patient.

For a variety of reasons, nowadays these societies are diverging from one another and act like competitors. Instead, these societies should unite and learn from each other. Harmonization rather than competition, should lead to collaboration and understanding between these societies. And this, of course, is to the benefit of the patient with a medical emergency, which brings us back to Hippocrates.

With this in mind, the World Association for Disaster and Emergency Medicine (WADEM) and the International Society for Disaster Medicine (ISDM) would like to set an example by joining their official publications into one single journal; Prehospital and Disaster Medicine. The Proceedings, for decades the official publication of ISDM, is no longer. Creating a real journal of $\mathrm{Di}$ saster Medicine was not realistic for the time being, because of the relatively small number of ISDM members and lack of manpower and finances to realize such an effort.

Therefore, as president of the ISDM, I have the privilege to introduce to all ISDM members this WADEM-ISDM official publication on Disaster and Emergency Medicine. And as a consequence, I would like to urge all members to submit papers on Disaster Medicine to Prehospital and Disaster Medicine. After all, this young branch on the old tree of Medicine has all the potentials in it to become a science! 


\section{AHA and Laerdal Announce New Partnership.}

he American Heart Association and Laerdal

Medical Corporation are proud to announce a new partnership which will provide the Emergency Cardiovascular Care (ECC) community with a centralized system of distribution for ECC training materials. Under the new partnership Laerdal will handle the distribution of all ECC related training materials.

The strength of the American Heart Association lies in researching the frontiers of science to prevent untimely death from heart disease and stroke. "As a result the Association has chosen to partner with Laerdal, who can focus on providing the highest quality customer support to help in the distribution of Emergency Cardiovascular Care materials," says Rodman D. Starke, MD, Senior Vice President of Science and Medicine.

Laerdal is renowned in the prehospital care market as a provider of innovative training products and resuscitation devices, including the Resusci ${ }^{\otimes}$ Anne family of CPR training manikins, the Heartstart ${ }^{\circ}$ line of Automated External Defibrillators (AEDs) and the HP CodeMaster 100 Portable Defibrillator/Monitor. Laerdal is also committed to support research and development projects in the field of acute care medicine.
ECC textbooks, as of July 1, 1997, will be updated to include new educational and scientific information on the following topics:

- Stroke and Acute Myocardial Infarction (ACLS Text)

- Tachycardia Decision Tree and AED (PALS Text)

- Air Bags and Auto Safety Seats (PBLS Text)

- Stroke and Public Access Defibrillation (BLS Healthcare Provider Text)

- Public Access Defibrillation (BLS Heartsaver Guide) In addition, ACLS, PALS, PBLS, BLS Healthcare Provider and BLS Heartsaver Guide text covers have been redesigned with new graphics and product dates, and will feature the new ECC logo.

Laerdal's commitment to providing AHA customers with the best possible customer service means:

- One-stop shopping for ECC training materials

- A variety of purchase options, including the use of purchase orders

- Speedy delivery

- Order status on request

The funds raised from the sale of ECC training materials will continue to support the mission of the American Heart Association.

For additional information or to order material call: 1-888-LMC-4AHA (562-4242) or fax your order to: $800-227-1143$.

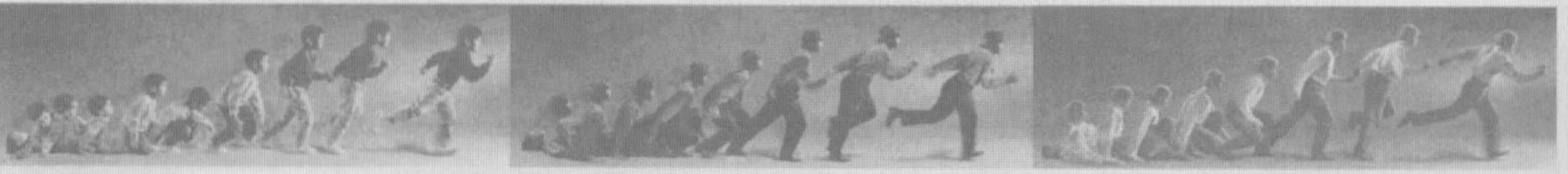

